\title{
TRANSFORMAÇÃO DA PAISAGEM E IMPACTOS SOCIOAMBIENTAIS NO BIOMA PAMPA
}

\section{Transformation of the Landscape and Social and Environmental Impacts on Pampa Biome}

\author{
Programa de Pós-Graduação em Geografia da Universidade Federal de Santa Maria \\ Cidade Universitária, Av. Roraima s/n, Camobi, , CEP 97100-000, Santa Maria (RS) - Brasil \\ Tel. (+ 55 55) 3220-8971 jacics@gmail.com \\ Programa de Pós-Graduação em Geografia da Universidade Federal de Santa Maria

\section{$a_{a} a a_{a}$}

Msc. Jaciele Karine Sell

Prof. Dr. Adriano S. Figueiró adri.geo.ufsm@gmail.com

\begin{abstract}
Resumo
Este artigo aborda questões relativas à singularidade do bioma Pampa no território gaúcho, historicamente excluído do projeto de desenvolvimento alcançado pela metade norte do estado, e que hoje se traduz nos nomes das grandes empresas de celulose e seus latifúndios de plantações de espécies exóticas de pinus, eucalipto e acácia. Objetiva-se questionar a lógica socioambientalmente insustentável destas monoculturas introduzidas na metade sul do estado - ressaltando-se aqui o município de Piratini- descrevendo e analisando os impactos negativos da sua presença sobre as condições naturais e de vida da população local. Tal atividade é hoje usada para inserir os municípios da região em um modelo desenvolvimentista dependente, que agrava ainda mais a crise socioambiental instalada, com a transformação profunda da estrutura da paisagem e a perda de significativo patrimônio natural. A abordagem adotada sugere a quebra desse pensamento único, dando ênfase ao debate em torno de uma mudança de concepção e de racionalidade com relação à qualidade de vida, qualidade ambiental e ao próprio desenvolvimento.
\end{abstract}

Palavras-chave: Bioma Pampa, Monoculturas, Árvores exóticas, Sustentabilidade.

\begin{abstract}
This paper aims discuss issues about to the originality of the Pampa biome in territory of the Rio Grande do Sul, historically excluded from the development project achieved by the northern region of the state, and which today is reflected in the names of the major pulp companies and their plantations of the exotic species of pine, eucalyptus and acacia. The aims is to question the logic of these socially and environmentally unsustainable monoculture introduced in the southern region of the state - and we point out here the municipality of Piratini- describing and analyzing the impacts of their presence on the natural conditions of life of local people. Such activity is now used to introduce the municipalities of the region on a dependent developmental model, which further aggravates the social and environmental crisis, with the profound transformation of landscape structure and the loss of significant natural heritage. The approach chosen suggests the breaking of these thought, emphasizing the discussion about the change of conception and rationality for the quality of life, environmental quality and the local development.
\end{abstract}

Key words: Bioma Pampa, Monocultures, exotic trees, sustainability

\section{Resumen}

Este artículo aborda preguntas relativas a una particularidad de la Campaña Gaucha, así como el proceso de construcción de su territorio, históricamente subordinado a la dinámica capitalista, y que hoy podemos traducir en nombres de grandes empresas de celulose y sus latifundios de plantaciones de especies exóticas. Objetivase cuestionar la lógica productiva de la monocultura de acacia, introducida en la mitad sur del estado - resaltando el municipio de Piratini - describiendo y haciendo un análisis de los impactos negativos de su presencia sobre las condiciones naturales y de la vida de la población de esta localidad. Tal actividad es utilizada hoy para inserir los municipios de la región en el modelo de desarrollo dependiente. El abordaje adoptado sugiere una ruptura de eso pensamiento único, dando un énfasis al debate en torno de un cambio de concepción y de racionalidad con relación a calidad de vida, calidad ambiental y al propio desarrollo.

Palabras Bioma Pampa, Monocultura, Árboles exoticas, Sustentabilidad.

\section{aaAaa}

Revista da ANPEGE, v. 7, n. 8, p. 129-141, ago./dez. 2011.

ISSN 1679-768 X @ 2003, Associação Nacional de Pesquisa e Pós-Graduação em Geografia. Todos os direitos reservados. 


\section{INTRODUÇÃO}

A paisagem extremamente singular da metade sul do Rio Grande do Sul tem sido alvo de acalorados debates com relação ao seu futuro. Já há algum tempo, indicadores de desenvolvimento ligados ao modelo hegemônico de produção capitalista vêm sendo adotados para caracterizar os municípios localizados nessa porção do território, denominando-a, na maioria das vezes, como sendo a "metade pobre" do estado. Tal afirmação, já bastante comum inclusive em alguns segmentos da comunidade acadêmica, reflete a maneira como se incorporou uma única maneira ou possibilidade de desenvolver-se, de evoluir: através da acumulação de capital supostamente desencadeada pela inserção do território na economia globalizada.

Diante de tal situação, diferentes modelos de desenvolvimento vêm sendo discutidos pelo poder público, pela iniciativa privada e pela sociedade organizada, dentre os quais, destaca-se neste trabalho o modelo agro-exportador baseado no latifúndio monocultor, através da implantação da silvicultura com espécies exóticas de pinus, eucalipto e acácia (SANTOS e TREVISAN, 2009). A situação torna-se ainda mais preocupante pelo fato de que o estereótipo de "metade pobre" está sendo usado como justificativa na administração e gestão das políticas públicas estaduais, haja vista as facilidades e atrativos disponibilizados pelos sucessivos governos às empresas multinacionais (que deixam muito pouco retorno para o município) para essa região, em nome do tão prometido e desejado (des)envolvimento .

Esta é a transformação por que vem passando dois terços do território do Rio Grande do Sul, que pode também ser definido como o pampa gaúcho. Com o objetivo de alimentar a indústria mundial de celulose, estão sendo implantadas vastas áreas de silvicultura, seguindo a tendência já presente em diversos outros países do Terceiro Mundo (CARRERE e LOHMANN, 2005), onde o rápido crescimento das plantas, o baixo preço da terra e da mão-de-obra, somados aos abundantes subsídios, se combinam para que a madeira resulte barata. Na figura 1, pode-se observar que o uso das terras para a plantação de eucaliptos no Brasil, já alcança o segundo lugar no planeta, ficando atrás apenas da Índia.

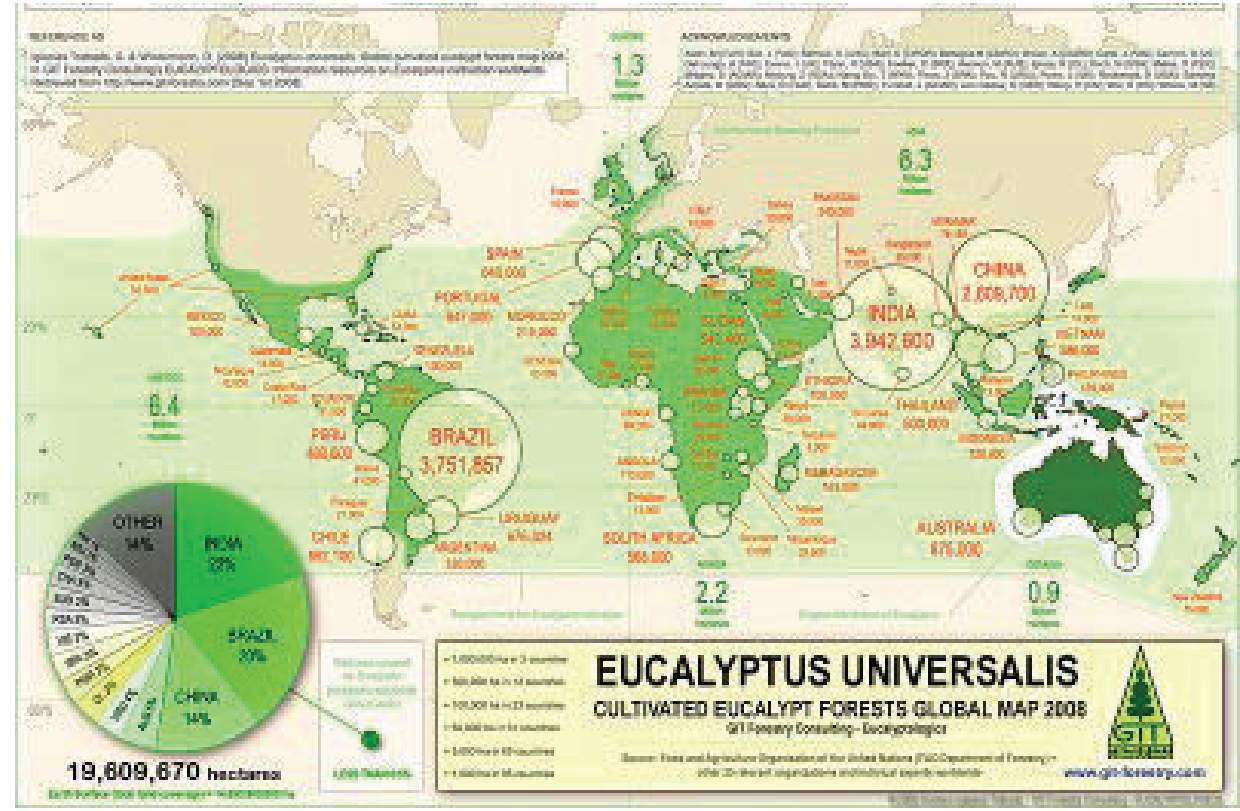

Figura 1- Mapa da quantidade de área plantada (em ha) de Eucaliptus sp. em diferentes países do mundo no ano de 2008. Observe-se a posição do Brasil, em segundo lugar no ranking internacional, pouco abaixo da Índia (primeira colocada).

Fonte: GIT Forest Consulting. Disponível em http://git-forestry-blog.blogspot.com/2007/10/eucalyptusinternational-global-plants.html 
À medida que os campos, as matas nativas e os solos agrícolas são invadidos por plantações de espécies exóticas, os resultados se traduzem - independente de estado ou país - em empobrecimento, degradação ambiental e conflitos no meio rural e urbano.

Buscando dialogar com esta realidade atual, em que essa região começa a experimentar a entrada no rápido processo de globalização, o presente artigo vai buscar discutir alguns aspectos socioambientais produzidos em decorrência desta dinâmica no município de Piratini . Em que pese o seu processo histórico-cultural ligado à pecuária extensiva, Piratini tem sido palco de profundas transformações na base produtiva atual, buscando alternativas à estagnação econômica promovida por aquela atividade.

No quadro destas transformações, e reproduzindo a mesma dinâmica que se instala em diversos municípios do sul do estado, percebe-se no município de Piratini claramente a emergência de um modelo de (des)envolvimento representado tipicamente por um processo de "modernização conservadora", buscando uma dinamização econômica do município sem alteração da base fundiária, com intensificação tecnológica e ampliação dos impactos socioambientais resultantes.

Desse modo, torna-se claro o objetivo do presente trabalho que procura, além de demonstrar a visão hegemônica e homogênea do processo de desenvolvimento presente no estado, também descrever e analisar os impactos negativos da presença do atual modelo sobre as condições naturais e de vida da população local no município de Piratini.

\section{METADE SUL NÃO É SINÔNIMO DE METADE POBRE}

É impossível falar em "metade sul” sem lembrar-se das grandes extensões de terras que ali se concentram. Tão necessário quanto remeter-se aos latifúndios e às marcas que estes deixaram (e ainda deixam) na sociedade, faz-se necessário também resgatar alguns fatos mais relevantes na formação histórica do território sul-riograndense, para que se possa efetivamente compreender como se constitui esta divisão entre o norte e o sul do estado.

Inicialmente, cabe lembrar que a economia do RS historicamente se baseou na criação de gado e, para fomentar a produção de carne e também propiciar a ocupação do território, a Coroa portuguesa efetivou a distribuição de Sesmarias ; primeiramente as doações eram feitas para os tropeiros e militares, consolidando assim a criação extensiva de gado nos latifúndios (Pesavento, 1997), não sendo necessário o seu pagamento, pois as mesmas eram doadas geralmente em troca de favores.

De acordo com Brum Neto (2007), a elevada concentração fundiária impedia o crescimento demográfico e era um obstáculo ao desenvolvimento da agricultura de subsistência. Os primeiros sinais de mudança desse quadro começaram a ocorrer com a chegada dos imigrantes na segunda metade do século XIX, que pouco a pouco introduziram a agricultura no estado e iniciaram um tímido processo de mudança da estrutura fundiária.

Para Zarth (2002), a imigração que ocorreu no norte do estado, nas áreas de florestas no planalto, só ocorreu ali para não mexer no latifúndio, o qual já havia se estabelecido anteriormente na parte sul do Rio Grande. Afirma o autor que:

(...) se o governo era adepto da colonização, os latifundiários tinham algumas restrições: colonização sim, mas sem mexer nas estâncias pastoris... dividir as matas sem mexer nos campos nativos foi a saída encontrada para resolver os problemas levantados e atribuídos aos latifúndios pastoris... Em 1921, a superfície colonizada, transformada em pequenas propriedades, era de $34.800 \mathrm{~km}^{2}$, conforme informa o Anuário Estatístico do RS daquele ano. E os campos nativos para criação de gado, segundo informa essa mesma fonte, ocupavam $180.000 \mathrm{~km}^{2}$.(ZARTH, 2002, p.72- p.73)

Além disso, para garantir a posse da maioria da terra sob o domínio dos grandes latifundiários e impedir que os lavradores nacionais, ex-escravos e imigrantes tivessem acesso a terra, instituiu-se no Brasil a Lei de Terras, a qual só permitia adquirir terras através da compra. Dessa maneira, a Lei de Terras foi fundamental para garantir a existência e o domínio do latifúndio na paisagem do 
Rio Grande do Sul. Criaram-se assim restrições legais ao desenvolvimento da agricultura familiar no país. Para Martins (2004, p. 137), este fato impôs sérios entraves ao desenvolvimento de um mercado interno mais robusto e manteve o direcionamento da produção das grandes propriedades (e de boa parte da economia brasileira, até os dias de hoje) voltada ao mercado externo.

Desse modo, pode-se notar que o processo de concentração fundiária não é algo recente, mas que decorre do processo histórico de ocupação do território do Rio Grande do Sul. Todo esse engessamento em torno da grande propriedade e da pecuária acabou deixando a região da Campanha à margem do processo de industrialização no estado, iniciado no final do século XIX, e que concentrou esse processo especialmente nas regiões de colonização alemã e italiana. Tal processo, somado às diferenças de produtividade do solo, às diferenças culturais e aos diferentes modos de produção contribuiu significativamente para a concretização do cenário atual do estado e, especialmente, da sua porção sul. Na esteira deste processo, o "atraso" econômico da metade sul, permitiu a este território, a preservação de um patrimônio natural e cultural já praticamente extinto ou profundamente alterado na porção norte do estado (BUBLITZ, 2006).

Todos esses breves apontamentos servem para, antes de tudo, retratar que a diversidade de paisagens do estado tem, para além do quadro físico, uma ancoragem histórica no processo de apropriação e transformação da natureza. Sendo assim, é difícil imaginar alguma possibilidade de êxito na insistência do poder público e privado em transformar a Campanha gaúcha por meio de modelos exógenos, idealizando nela o desenvolvimento de processos que ignoram sua história e seu patrimônio, acreditando que um dia ela se torne tão capitalizada e (des)envolvida quanto o planalto norte. A região pode sim se desenvolver, transformar-se em uma referência de qualidade de vida, ambiental e também de crescimento econômico, porém valorizando suas próprias características,

132 as potencialidades próprias do seu meio natural e da sua cultura. Porém, para isso, precisa deixar de ser vista apenas sob o olhar único do capital globalizado, de exploração e de geração de lucro.

\section{O SUFOCAMENTO DA BIO-SOCIODIVERSIDADE LOCAL}

Todo o discurso de "pobreza" da metade sul que é vendido à população riograndense, é, antes de mais nada, conseqüência do modo único de percepção, da constatação de um fato ou fenômeno de apenas um único ponto de vista, numa espécie de "monocultura do pensamento". Shiva (2003) corrobora com tal constatação quando afirma que antes de se inserir no solo, uma monocultura domina o pensamento das pessoas, em uma forma de monocultura da mente. É possível afirmar que os indicadores daquilo que é visto como desenvolvimento, prosperidade e sucesso é produzido de forma globalizada a partir de uma espécie de monocultura (NOVO, 2007). Uma monocultura, pois todos recebem a mesma semente, devem cultivá-la da mesma maneira até oferecer os frutos desejados, que também devem ser idênticos uns aos outros; caso contrário, serão descartados imediatamente. A semente, neste caso, é o pacote de desenvolvimento, fechado, sem qualquer possibilidade de uma cidade ou região evoluir de uma maneira diferente, a seu modo e de acordo com suas necessidades e capacidades. Para a semente do desenvolvimento crescer, é preciso 'cultivá-la' com muito concreto, buzinas, cores, sons, anúncios, luzes; caso contrário, os frutos esperados não virão, e esta cidade será também descartada, ou classificada como inferior, pobre e subdesenvolvida, produzindo aquilo que Nogué (2007) chama de "territórios sem discurso" e "paisagens sem imaginário".

Essa monocultura do pensamento faz com que todo o potencial de biosociodiversidade existente na porção sul do território gaúcho seja esquecida, negligenciada, pois, afinal, ela não oferece lucro imediato às empresas, ela não injeta capital no mercado, ela funciona sob outra lógica, sob outro tempo.

A metade sul do estado e, logo, o município de Piratini, coincide com a área de abrangência do bioma pampa. Este bioma (IBGE apud Suertegaray e Pires da Silva, 2009), é a reunião de "formações ecológicas que se intercruzam em uma formação ecopaisagística única, com intenso 
tráfego de matéria, energia e vida entre os campos, matas ciliares (de galeria), capões de mato e matas de encostas".

Estimativas recentes indicam que esta região é composta de pelo menos 3.000 plantas vasculares, com 450 espécies de gramíneas e 150 de leguminosas, além de 385 aves e 90 mamíferos, sendo parte destas espécies chamadas endêmicas, pois só ocorrem neste ecossistema. É por isto que os campos pampeanos, na sua composição de flora e fauna, podem ser considerados tão importantes quanto uma floresta tropical, para a conservação da biodiversidade planetária. (PICOLLI e SCHNADELBACH, 2007)

No entanto, da sua vegetação campestre e dos seus banhados característicos, restam apenas 39\% (Picolli e Schnadelbach, 2007). Entre os anos de 1970 e 2005, segundo as autoras (op. cit.), estima-se que 4,7 milhões de hectares de pastagens nativas foram convertidos em outros usos agrícolas, como lavouras e plantações de árvores exóticas. Esta violenta supressão da vegetação campestre natural do Pampa gaúcho torna-se ambientalmente ainda mais grave diante da imensa riqueza da biodiversidade nela existente.

É essa diversidade, suas paisagens e a sua cultura que se encontram ameaçadas. A proposta da silvicultura como alternativa desenvolvimentista, contrária às propostas de manutenção da diversidade através do uso diversificado e da manutenção desse mosaico de paisagens, saberes e fazeres vem revelando o embate (SUERTEGARAY e PIRES DA SILVA, 2009).

Shiva (2003), ao tratar de uma dinâmica globalizada do capital, fala da situação indiana com a mesma clareza como se estivesse fazendo a leitura do processo desencadeado na metade sul do Rio Grande do Sul. Inicialmente convenceram as pessoas/mentes de que eram pobres, subdesenvolvidas, atrasadas e que para serem felizes, para obterem qualidade de vida, precisariam seguir o padrão da cultura global, dos países e das cidades desenvolvidas. Posteriormente, a monocultura se instalou no solo, na forma de lavouras de espécies exóticas e passou a ser um sopro de esperança para as mentes dominadas; afinal, ela iria supostamente transformar a região, (des)envolvendo-a.

No entanto, nestas monoculturas, "não há possibilidade alguma de existir vida diversificada, intercâmbio biológico, cadeia alimentar e condições naturais que permitam a sobrevivência, até mesmo, do mais rasteiro dos insetos" (PEREIRA, 2006, p.08 ).

...embora seja um dos pilares de sustentação da moderna agricultura capitalista a monocultura revela, desde o início, que é uma prática que não visa satisfazer as necessidades das regiões e dos povos que produzem. A monocultura é uma técnica que em si mesma traz uma dimensão política, na medida em que só tem sentido se é uma produção que não é feita para satisfazer quem produz. Só um raciocínio logicamente absurdo de um ponto de vista ambiental, mas que se tornou natural admite fazer a cultura de uma só coisa. (PORTO-GONÇALVES, 2006, p.28).

Chomenko (2007) contribui salientando que, ao mesmo tempo em que o Brasil depende diretamente do uso de bens da biodiversidade, também é o país campeão mundial de perda de biodiversidade. Para ilustrar a situação, a pesquisadora tráz o exemplo do Rio Grande do Sul que, em função de sua diversidade de clima, solos, relevos, possui diferentes ecossistemas que, além do processo histórico de ocupação, possibilitam distintos usos antrópicos. Na distinção clássica entre norte-sul, a primeira caracteriza-se pela alta concentração antrópica, pelo seu elevado grau de (des) envolvimento e pela utilização intensa do solo com agricultura, o que acaba resultando na descaracterização do Bioma Mata Atlântica. Do outro lado, a vegetação e animais presentes na metade sul do estado, também vem sendo identificada como uma "matriz altamente preocupante, que se caracteriza em termos de cenários e tendências futuras a expansão da degradação".

Esses processos de desenvolvimento que vem sendo implantados na região, buscando benefícios imediatos, podem levar a conclusão de que o Bioma Pampa sofrerá as mesmas conseqüências que o Bioma Mata Atlântica na metade norte do estado, tendo em vista as ações não sustentáveis que vem sendo planejadas e efetuadas na região, tanto sob aspectos socioeconômicos, quanto 
ambientais e culturais. Além disso, a implantação de um modelo totalmente dependente de fatores externos, desde aquisição de mudas, insumos agrícolas, comercialização, até variações em bolsas de valores, não traz garantia nenhuma de melhoria de vida para a população local. Ao contrário, o cultivo de monoculturas de espécies exóticas em grandes extensões de terra, mantém a estrutura fundiária (baseada no latifúndio, na desigualdade e na concentração) e conduz a graves conflitos, que tenderão a ser cada vez mais acentuados, seja pelo uso de recursos escassos, seja pela posse da terra ou ainda pela própria perda da identidade cultural regional, como discutiremos a seguir.

\section{TRABALHADORES, EMPRESAS E MEIO AMBIENTE EM UMA REGIÃO DE PLANTAÇÕES DE ACÁCIA}

Por meio da coleta de dados e trabalhos de campo no município de Piratini, foi possível identificar quais as alterações que a inserção do modelo econômico agroexportador realiza sobre este espaço, contrapondo-se ao perfil do discurso oficial dominante e permitindo entendê-lo como palco de uma disputa entre modos contraditórios de usar e viver a terra, que se opuseram e que ainda se opõe no quotidiano da região.

A partir das observações e dos relatos dos moradores e demais sujeitos envolvidos na pesquisa, essa região pode ser descrita sumariamente como sendo um lugar ocupado em sua maior parte por descendentes indígenas e que se manteve à margem do modelo de desenvolvimento constituído há mais de 50 anos (figura 2). Sendo assim, conserva uma série de características e elementos, como a paisagem, os recursos naturais, a cultura e os saberes tradicionais, algumas formas de produção "pré-modernas" (justamente por não ter incorporado os padrões da modernização da agricultura) e que no seu conjunto podem constituir um potencial enorme para estratégias de desenvolvimento realmente sustentável.

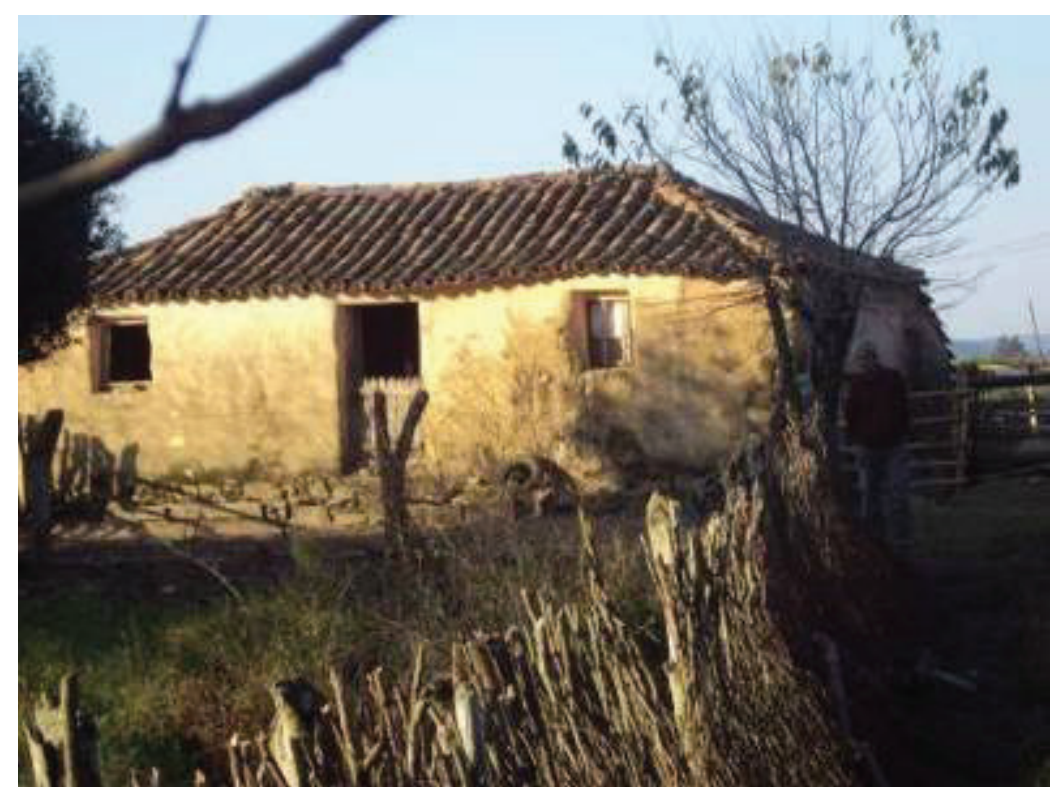

Figura 2 - Casa comumente encontrada na comunidade do "Paredão". Ao lado, seu morador, descendente de indígenas/escravos.

O esgotamento das possibilidades de extração mineral de cassiterita na comunidade, atividade principal dos moradores até a década de 1980-1990, coincidiu com a entrada das primeiras lavouras de acácia na região. Em um primeiro momento, a chegada das empresas parecia ser a solução dos problemas da comunidade, visto que esta se localiza em uma área de terrenos muito íngremes e de baixa fertilidade para produção agrícola. Porém, segundo relatos dos próprios moradores, foi apenas na primeira plantação e (após sete anos) na primeira colheita que a empresa fez uso de mão-de-obra 
local. A falta de oportunidade e de incentivo para permanência no campo acabou por estimular os moradores a migrarem para cidade, vendendo suas terras a um preço irrisório às empresas de "florestamento".

Compreendido o processo de inserção das lavouras nas comunidades, buscou-se esclarecer o processo produtivo através de três eixos: impactos ambientais, impactos na sociedade e na cultura e políticas públicas. Para isso, ouviram-se quatro diferentes segmentos da sociedade envolvidos no processo: 1 - produtor de acácia, 2 - empresa(s), 3 - produtor de carvão e 4 - informantes qualificados da comunidade.

Antes de aprofundar as discussões acerca das conseqüências causadas pelo modelo em estudo, é importante contextualizar e descrever brevemente cada um dos informantes. No primeiro caso, trata-se de um produtor, advindo de outra cidade, já aposentado, cuja renda para sobrevivência (sua e de sua família) não depende do meio rural, tornando as atividades ali desenvolvidas um hobbie, como ele mesmo afirma. O tamanho total da propriedade é de 4.500 hectares, porém destes apenas 1.500 hectares são destinados a produção de acácia, os demais abrigam criação de gado zebu, búfalos e eqüinos de raça. Não fugindo à realidade local, o proprietário adquiriu vários lotes de terra, de diferentes famílias que abandonaram o campo, pagando de $\mathrm{R} \$ 10,00$ a $\mathrm{R} \$ 40,00$ por hectare.

$\mathrm{O}$ segundo caso remete-se à empresa que atua especificamente na região sudeste do estado. Ela atua na área florestal, especificamente no plantio de acácia e exporta em média, 750 mil toneladas de cavaco de madeira para o mercado asiático por ano. Sua sede fica no município de Montenegro (RS) com escritórios em 20 outros municípios, incluindo Piratini, e totaliza uma área plantada de 57 mil ha no estado. É importante ressaltar que esta empresa se envolve diretamente apenas na etapa de controle das pragas (exige pessoal capacitado) e pela colheita, em função do uso de uma máquina de alto valor e manutenção. As demais etapas, como cultivo das mudas, preparo do solo, plantio, corte, baldeio (empilhamento) e transporte é realizado por empresas terceirizadas. Quando da realização do trabalho de campo, as áreas da empresa na região estavam passando pelo processo de baldeio, e encontravam-se no local várias empresas menores, que também não aproveitam a mão-de-obra local, pois são provenientes de outros municípios, inclusive de outro estado, e fazem a captação de trabalhadores nos seus municípios de origem.

Quanto ao produtor de carvão, salienta-se que este é morador nascido na comunidade e que trocou o cultivo de feijão pelos fornos de carvão. Não possuindo plantação própria, apenas compra a madeira descartada pela empresa, galhos e troncos que estão fora do padrão de exigência (sendo chamados de "metrinho") e as queima em 5 fornos próprios. Segundo o produtor, "cerca de $5 \%$ da madeira colhida em cada propriedade vai para o metrinho".

Com relação à comunidade, visitou-se o terceiro subdistrito, Capela, dentro do qual a localidade de Paredão divide-se em pequenas comunidades, Costa do Bica, Rincão do Laço e Minas do Paredão. Essas comunidades encontram-se a cerca de $100 \mathrm{~km}$ de distância da sede do município, o que culminou em um relativo distanciamento das ações do poder público.

Os sujeitos em questão, conforme já salientado anteriormente, são resultado da miscigenação entre índios guaranis/charruas e descendentes de portugueses, africanos e espanhóis. Na sua maior parte, se dedicam às atividades agrárias, onde merece destaque sua organização produtiva que é baseada na pecuária familiar, na tradicional criação de ovinos e bovinos e, numa agricultura de subsistência com destaque para a produção de milho e feijão, que representam a principal rede comercial e social desses agricultores em escala regional. Cabe salientar que grande parte dos moradores destas comunidades não possui documento oficial de propriedade da terra, podendo ser identificados como posseiros, o que em muito dificulta qualquer processo de financiamento ou custeio de sua produção.

A partir dos relatos dos atores acima citados, foi possível descrever um panorama geral da situação que se encontra essa região do município de Piratini. Ousa-se aqui afirmar que esta caracterização não foge da realidade encontrada no restante da Campanha Gaúcha onde tal projeto de modernização tem avançado. 
Primeiramente, abordar-se-ão questões relativas às interferências que tais lavouras de acácia trazem para o meio natural local.

A primeira característica, que burla não só a legislação ambiental, mas as leis da própria natureza é o modo de plantio. Por ser uma área de declividade acentuada, seria necessário o plantio em curvas de nível, o que certamente diminuiria a perda de solo por erosão e/ou lixiviação. Na figura 3D o sentido dos tocos que restaram após a colheita demonstram claramente o sentido da plantação. Além disso, o sub-bosque destas áreas com densa invasão é praticamente inexistente, aumentando a suscetibilidade para erosão e, passado o corte/colheita, as grandes áreas ficam expostas às ações da água e do vento, aumentando ainda mais o processo erosivo. Mochiutti (2007) alerta também para o fato de que são estas áreas de plantio que apresentam maiores requerimentos por água em relação à vegetação nativa, o que acaba reduzindo o fluxo das águas e a vazão dos rios.

As lavouras ocupam topos de morro (Figura 3B), encostas dos arroios e rios (Figura 3A) e até mesmo as estradas, causando graves conseqüências nas instalações da rede de energia elétrica e na circulação de pessoas. Se não bastasse, em alguns trechos a empresa construiu portões/porteiras interditando a estrada, dando a entender que ao ultrapassar a barreira, adentrava-se em uma área particular.

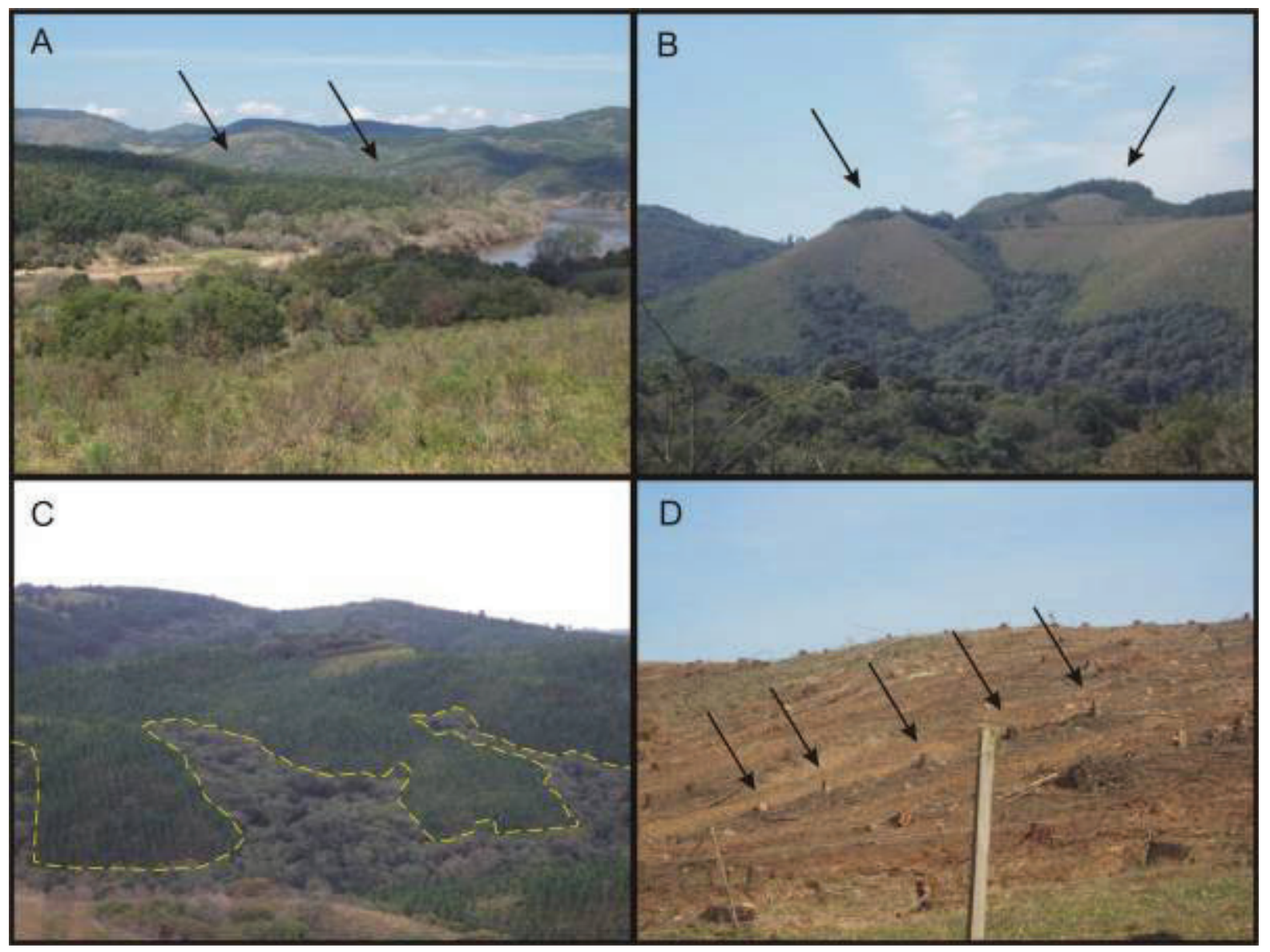

Figura 3 - Impactos visíveis das lavouras de acácia no ambiente natural do município de Piratini. (A) O plantio se estende até as margens do rio Camaquã, desrespeitando as Áreas de Preservação Permanente ao longo das margens; (B) as áreas de topo de morro, consideradas pelo Código Florestal como APPs, também são utilizadas para o plantio de acácia; (C) não há nenhuma zona de proteção que impeça a migração da espécie exótica, mais agressiva, para dentro da mata nativa que se desenvolve em fundos de vale, modificando o padrão estrutural e a dinâmica ecológica neste ecossistema; (D) o plantio ao longo das vertentes não obedece às curvas de nível do terreno, desencadeando grandes processos erosivos no período pós-colheita.

Como pode ser observada na figura $3 \mathrm{C}$, também não há zona de amortecimento entre uma área plantada e uma área de mata nativa. Elas estão se sobrepondo sem nenhuma preocupação com 
a conservação de corredores ecológicos, com o habitat natural da fauna e da flora local ou ainda com a própria dinâmica dos ecossistemas. Outro exemplo que pode ser vislumbrado é a invasão das caturritas (Myiopsitta monachus), consideradas como uma praga pelos moradores, que são atraídas pelas lavouras de acácia e, ao entrarem na mata nativa, alteram a dinâmica natural das espécies que ali habitam. Essas interferências fazem com que muitos animais deixem a mata nativa, acuados, e acabem invadindo as propriedades da região. Na percepção dos moradores, "Os bicho tão tudo assustado, já não tem mais pra onde ir, tão acabando com os mato, aí aparecem aí no pátio das casa". Já os técnicos da empresa fotografam pacas, veados-virá, gatos-maracajá, lontras, quatis (Figura 4), e se orgulham afirmando: "Nunca tinha desses bichos por essas áreas, são animais que estão em risco de extinção e que nós cuidamos aí nas propriedades". Obviamente tais espécies nunca eram vistas tão comumente pela região, pois estavam abrigadas em seu habitat natural, não necessitando buscar alimento ou refúgio em áreas habitadas.

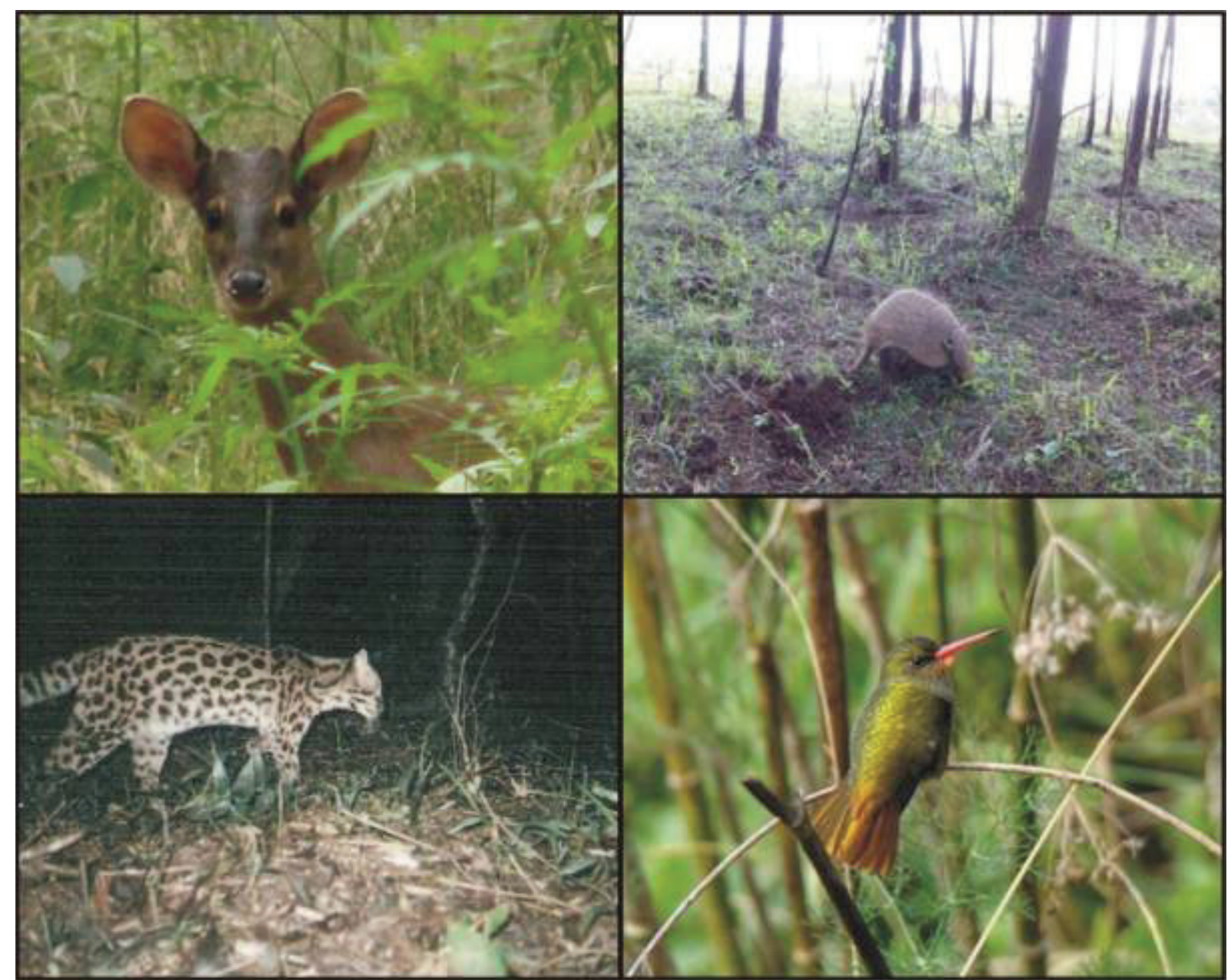

Figura 4 - Algumas espécies da fauna local que estão perdendo seu habitat natural e que acabam 'aparecendo' nas lavouras de árvores e até mesmo nas residências próximas.

Fonte: Resumo Público de Monitoramento - TANAGRO

Além da fauna, algumas espécies da flora que se encontram nas áreas de plantio de acácia estão ameaçadas de extinção, tais como aroeirão, pinheiro-brasileiro, butiá, canela amarela, etc. Segundo Mochiutti (2007) a acácia-negra é considerada uma invasora de ambientes naturais, sendo classificada entre as 100 espécies exóticas com maior potencial invasor do mundo. Segundo o autor, diversas características biológicas a capacitam como invasora, dentre os quais se destacam: grande produção de sementes que podem ser dispersas pela água e outras formas não intencionais; sementes apresentam dormência, permanecendo viáveis por longos períodos; queima e distúrbios no solo induzem a germinação e o estabelecimento das plantas, além do seu rápido crescimento. 
Sendo assim, uma das maiores preocupações com as plantações florestais é a capacidade destas em causar impactos pela alteração de habitats naturais, redução da biodiversidade e alteração fisionômica da paisagem.

Outra característica que não pode deixar de ser lembrada, e que inclusive está muito presente nas reclamações da comunidade local, é a fumaça, tanto a oriunda da queima da madeira para produção do carvão (Figura 5A) quanto a da queima dos galhos e restos das árvores que não tem aproveitamento comercial (Figura 5B). As próprias empresas assumem a queima ilegal deste material, mesmo quando a Secretaria de Estado de Agricultura e Abastecimento institui através da resolução 026 de 2002 que "É expressamente proibida a queima de qualquer material vegetal à guisa de limpeza de área, e de material lenhoso quando seu aproveitamento é economicamente inviável."

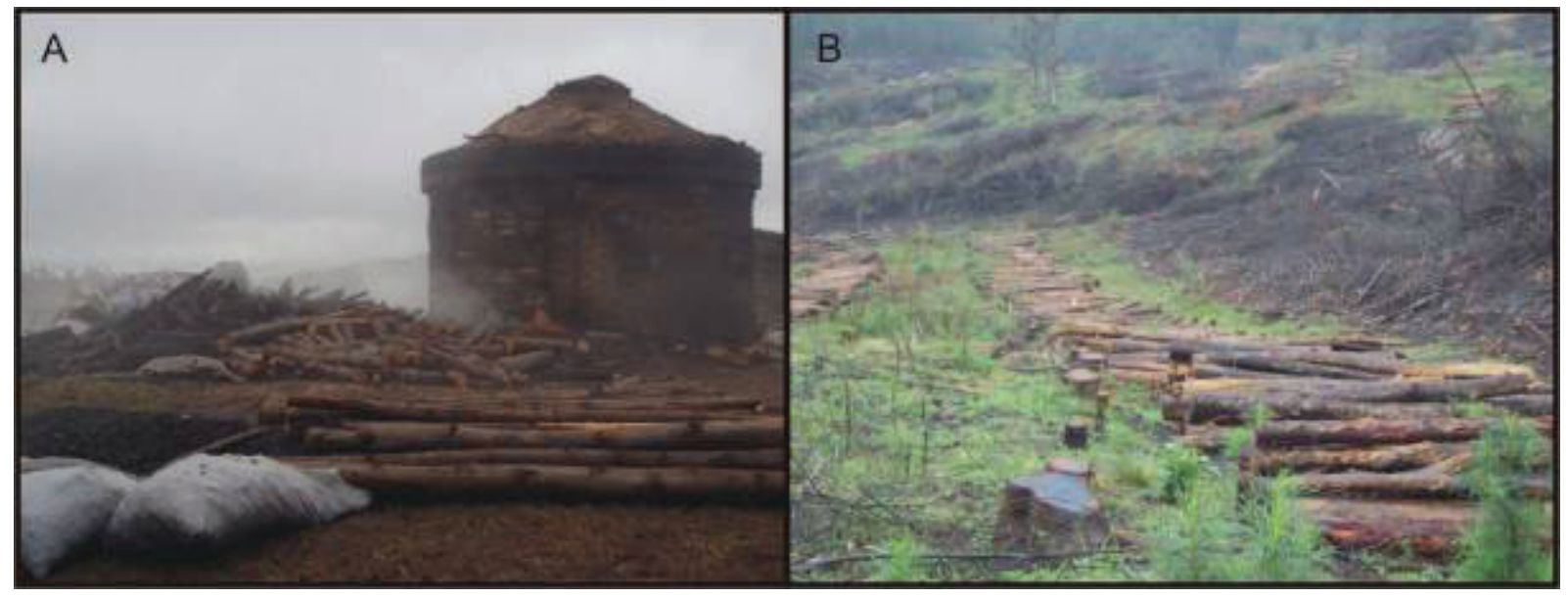

Figura 5 - Para além dos impactos relacionados ao plantio e crescimento destas lavouras de árvores exóticas, o período pós-colheita também acarreta significativos impactos com o descarte da madeira não aproveitada como produto principal. (A) Forno usado para a transformação da madeira descartada em carvão; (B) Material excedente na lavoura gera impacto na paisagem e muitas vezes é queimado a céu aberto.

Já se tratando de questões ligadas ao eixo sociedade e cultura, torna-se primordial ressaltar a expulsão da população rural e a especulação do mercado imobiliário. Se antes as populações abandonavam o campo em função do esgotamento do solo, da falta de recursos, assistência e incentivos para produção agrícola e pelo fim da exploração mineral local, hoje elas são "tentadas" a vender suas propriedades para as grandes empresas que pagam valores "altíssimos" no contexto local. Propriedades que antes eram comercializadas a $\mathrm{R} \$ 10,00$ o hectare, hoje são compradas por até $\mathrm{R} \$ 300,00$.

Considerando o fato de que as propriedades familiares das comunidades não passam dos 50 ha, as áreas da empresa e até mesmo do proprietário entrevistado poderiam ser ocupadas por dezenas de famílias. De acordo com o relato de um pequeno produtor local de carvão que foi entrevistado, o plantio das mudas foi realizado com mão-de-obra local, cerca de 8 pessoas, e com auxílio de 4 tratores, por um período de aproximadamente 2 meses. Ao considerar-se o tamanho médio da família brasileira, em torno de 3,3 pessoas (IBGE, 2000), a mesma área (1500ha) que empregou 8 pessoas, por um breve espaço de tempo, poderia ocupar mais de 100 pessoas, durante todo o ano produtivo, gerando emprego, renda e alimentos.

Isso demonstra o quão ínfimo é o retorno desse modelo para a comunidade local. Avançando na análise, pode-se citar o fato de que na primeira colheita, a empresa (para cumprir com seu discurso desenvolvimentista) levou para a região 400 trabalhadores para atuarem no corte das árvores. Hoje, independente do tamanho da área cultivada, essa função é realizada apenas por uma máquina e um funcionário por turno de trabalho. O processo de terceirização também contribuiu muito para a não inserção da comunidade local no processo produtivo, pois as empresas vêm de outros municípios, já com suas equipes de trabalho montadas. Essa diminuição do compromisso com as comunidades 
locais e com a geração de empregos propriamente dita pode ser contemplada na tabela que segue (Figura 6). Nota-se uma significativa diminuição do número de colaboradores da empresa, tanto diretos quanto indiretos, demonstrando que não é o processo de terceirização o único responsável pela diminuição da oferta de emprego pelas empresas. Além disso, o aumento das despesas com atendimentos médicos e/ou odontológicos per capita, ou seja, por colaborador ( $\$ 214,00$ por trabalhador em 2006 e R $\$ 312,00$ em 2009), além de representar um aumento nos custos destes serviços, pode representar um aumento de exposição aos riscos por parte dos trabalhadores. Isso pode justificar-se em parte pela intensificação do contato desses trabalhadores com máquinas, em decorrência de todo processo de tecnologização do processo produtivo e também pelo contato com agrotóxicos, cada vez usado em maior quantidade nas lavouras.

\begin{tabular}{|c|c|c|c|c|}
\hline INDICADORES & \multicolumn{5}{|c|}{ ANO } \\
\hline Colaboradores diretos e indiretos & $\mathbf{2 0 0 6}$ & $\mathbf{2 0 0 7}$ & $\mathbf{2 0 0 8}$ & $\mathbf{2 0 0 9}$ \\
\hline Horas de treinamento & 1.035 & 879 & 938 & 426 \\
\hline Afastamento por lesão & 10.375 & 22.429 & 9.274 & 3.386 \\
\hline Absenteísmo (Colheita) & 92 & 50 & 22 & 18 \\
\hline Absenteísmo (Silvicultura) & $1,98 \%$ & $1,76 \%$ & $2,26 \%$ & $1,26 \%$ \\
\hline Atendimentos médicos / odontológicos & $\mathrm{R} \$ 221.665$ & $\mathrm{R} \$ 181.507$ & $\mathrm{R} \$ 204.315$ & $\mathrm{R} \$ 133.100$ \\
\hline Reclamatórias trabalhistas & 22 & 7 & 7 & 12 \\
\hline
\end{tabular}

Figura 6 - Investimento em recursos humanos da empresa Fonte: Resumo Público do Monitoramento - TANAGRO

Portanto, os únicos moradores da comunidade que se envolvem de alguma maneira com o processo de produção de árvores, são as cinco pessoas que trabalham na queima do carvão e que são contratadas, sem nenhum registro oficial, pelo próprio morador da comunidade.

Essa indiferença com relação à comunidade local é reforçada ainda mais pelo fato de que a empresa não compra a produção de madeira de áreas menores que 30 ha. Sendo assim, os pequenos agricultores que resistiram à onda de abandono do campo e que acreditaram no desenvolvimento através das lavouras de árvores, acabam frustrados por não terem, depois de sete anos de espera, mercado para vender sua produção.

Por esse e por outros motivos - como o sucateamento das estradas pelo excessivo peso das máquinas e carretas carregadas que circulam na região e pela degradação da rede de energia elétrica, ocasionada pela queda de árvores - percebe-se que, atualmente, a população local mais diretamente vulnerável aos impactos da monocultura, se posiciona extremamente contra este modelo que foi adotado. Em seus relatos, questionam principalmente com relação a não geração de renda e a falta de alimentos (produção) na região. Nota-se que toda a expectativa que fora criada quando da inserção das lavouras na comunidade, hoje já não se faz mais presente. Inicialmente acreditava-se que haveria uma melhoria nos padrões de vida dos moradores, que estas lavouras trariam realmente o desenvolvimento para a região, porém, com o passar dos anos, a própria população vem se questionando sobre quais as vantagens dessa mudança. Percebem, portanto, que nenhuma mudança efetivamente se concretizou; que sua situação é de total dependência de programas sociais do governo e muito pouco tem sido feito por parte do poder público para melhoria das condições locais. Esta condição pouco difere dos impactos produzidos pelas monoculturas introduzidas na Índia em décadas anteriores (SHIVA e BANDYOPADHYAY, 1983). 
Assim, é possível adentrar no debate em torno das políticas públicas que vêm gerindo o modelo atual de (des)envolvimento em implantação na metade sul do estado. A falta de programas que incentivem a organização da comunidade em torno de seus próprios objetivos, necessidades e potencialidades, acaba por não melhorar as condições de vida daquelas populações, intensificando sua saída do campo. Por outro lado, o conformismo com a situação de pobreza, a auto-imagem de subdesenvolvimento que lhes foi plantada, acaba por impedir um processo de mobilização e de luta coletiva para reivindicar mudanças/melhorias.

Acomodado diante dessa desorganização de energia, de força e de potencial social, o poder público acaba cedendo, aliviado, às grandes empresas que, com auxílio pesado da mídia, pressionam a todo o momento, clamando por incentivo e afirmando-se como sendo as portadoras da chave da evolução, do (des)envolvimento.

\section{CONSIDERAÇÕES FINAIS}

O modelo de desenvolvimento adotado para a metade sul é reflexo de um processo infindável de busca que já acontece há mais de meio século e que somente agregou problemas para a maioria das sociedades que o adotou. É chegada a hora da superação desse "paradigma" da modernidade, pois para que uma sociedade sustentável realmente exista, são necessários muito mais do que a acumulação de bens e serviços; é preciso pensar de uma maneira qualitativa na qualidade de vida e na felicidade das pessoas. Vai muito além das relações materiais de mercado estabelecidas pelas nações em nível global; é necessário voltar-se para uma escala mais local, visando a subsistência da população através do que lhes é tido como importante, como essencial. Para que uma real sustentabilidade exista, é preciso que o sistema econômico esteja subordinado às leis naturais e aos critérios de respeito e dignidade humana.

A subordinação histórica do território sulriograndense à lógica capitalista tem mostrado as inúmeras tentativas frustradas e conseqüências negativas que a adoção de pacotes externos representa. Seja no norte ou no sul do estado, pacotes desenvolvimentistas, totalmente dependentes e prontos, muito pouco contribuem para a melhoria de vida da população local. Podem até possibilitar o acesso de determinados grupos sociais a 'regalias' materiais, a uma pseudo qualidade de vida, porém já é possível observar fragilidades nesse processo, sejam elas a curto, médio ou longo prazo, nas questões sociais ou ambientais (se é que podem ser separadas). Mesmo assim, com índices de violência, criminalidade, suicídio e doenças psicológicas aumentando nessas áreas ditas (des)envolvidas, ainda insistem (poder público e/ou privado) na implantação do mesmo modelo na porção sul do estado. Uma região que possui outro processo de ocupação histórica, outras características naturais, outra construção social, outra cultura, e que está sendo obrigada a "engolir" um programa de (des) envolvimento e aceitar que outras pessoas digam como e quando elas devem sentirem-se felizes.

Assim, é necessário reafirmar que a transformação em sua totalidade depende de alternativas que contestem os impactos e as limitações advindas com os modelos de desenvolvimento e modernização impostos. Para a sustentabilidade, o que efetivamente se requer, são ações que dialoguem com o lugar e com os do lugar (LIMÃO et al, 2006), e não que se imponham do alto, de fora.

\section{REFERÊNCIAS BIBLIOGRÁFICAS}

BRASIL - INSTITUTO BRASILEIRO DE GEOGRAFIA E ESTATÍSTICA. Disponível em www.ibge.gov. br. Acesso em 04 de out. de 2010.

BRUM NETO, H. Regiões culturais: a construção de identidades culturais no Rio Grande do Sul e sua manifestação na paisagem gaúcha. 2007. 328f. Dissertação (Mestrado em Geografia) - Universidade Federal de Santa Maria, Santa Maria, 2007.

BUBLITZ, J. Desmatamento Civilizador: A História Ambiental da Colonização Européia no Rio Grande do 
Sul (1824-1924). III Encontro da ANPPAS. Anais... Brasilia: ANPPAS, 2006

CARRERE, R.; LOHMANN, L. EI Papel del Sur. Plantaciones forestales en la estratégia papelera internacional. Montevideo: Sn, 2005.

CHOMENKO, Luiza. Pampa: Um Bioma em extinção. Revista do Instituto Humanitas Unisinos. São Leopoldo, ed.247, p. 4-8, dez 2007. Disponível em: www.ihuonline.unisinos.br. Acesso em 25 fev. 2010.

LIMÃO, J.; ARANHA, M.R.; SANTOS, P.M. Ordenamento do Território e Desenvolvimento Rural. Lisboa: LEADER+, 2006.

MARTINS, José de Souza. Os camponeses e a política no Brasil. Petrópolis: Editora Vozes, 1981.

MORAES, R. C. . Metade Sul vs Metade Norte: Uma Comparação a partir de Dados Municipais do Rio Grande do Sul. $3^{\circ}$ Encontro de Economia Gaúcha. Anais... Porto Alegre, RS : PUCRS, 2006. p. 1-22.

MOCHIUTTI, Silas. Produtividade e Sustentabilidade de plantações de Acácia-Negra (Acacia mearnsii De Wild.) no Rio Grande do Sul. 286 f. Tese de Doutorado (Doutorado em Ciências Florestais) - Universidade Federal do Paraná, Curitiba. 2007.

NOGUÉ, J. Territorios sin discurso, paisajes sin imaginario. Retos y dilemas. Ería, 73-74: 373-382. 2007.

NOVO, M. El Desarrollo Sostenible. Su dimensión ambiental y educativa. Madrid: Prentice Hall, 2007. PEREIRA, P. Dossiê Deserto Verde - O Latifúndio do Eucalipto. Porto Alegre: NatBrasil, 2006.

PESAVENTO, S. J. A história do Rio Grande do Sul. Porto Alegre: Ed. Mercado Aberto, 1997.

PICOLLI, L.R., SCHNADELBACH, C. V. [coord.] O Pampa em Disputa: A biodiversidade ameaçada pela expansão das monoculturas de árvores. Porto Alegre: Amigos da Terra Brasil. 2007.

PORTO-GONÇALVES, C. W. A globalização da natureza e a natureza da globalização. Rio de Janeiro: Civilização Brasileira, 2006.

SANTOS, T.; TREVISAN, R. Eucaliptos versus bioma Pampa: compreendendo as diferenças entre lavouras de arbóreas e o campo nativo. In: TEIXEIRA FILHO, A. (Org.). Lavouras de Destruição: a (im)posição do consenso. P.299-332. Petolas: snt, 2009.

SELL, J.C. Diferentes modelos, diferentes caminhos: problematizando a sustentabilidade ambiental no município de Piratini, RS. Dissertação de Mestrado (Mestrado em Geografia)- Universidade Federal de Santa Maria, Santa Maria. 2011.

SHIVA, V.; BANDYOPADHYAY, J. Eucalyptus - a disastrous tree for India. Ecologist, 13 (5): 184-187, 2003. SHIVA, V. Monoculturas da Mente: perspectivas da biodiversidade e da biotecnologia. São Paulo: Gaia, 2003.

SUERTEGARAY, D.M.A., PIRES DA SILVA, L.A. Tche Pampa: Histórias da natureza Gaúcha. In PILLAR, V.P... [et. al]. Editores. Campos Sulinos: Conservação e uso sustentável da biodiversidade. Brasília: MMA, 2009.

ZARTH, P. A. Do Arcaico ao Moderno - O Rio Grande do Sul Agrário do Século XIX. Ijuí: Edidora UNIJUÍ, 2002.

Trabalho enviado em novembro de 2011

Trabalho aceito em dezembro de 2011 